\title{
The impact of lower urinary tract symptoms on the quality of life during pregnancy: a cross- sectional study from Palestine
}

\author{
Qais T. Ahmad' ${ }^{\text {, Jaffar H. Saffarini }}{ }^{1}$, Ahmad M. Samara' ${ }^{\text {, Dima S. Jabri }}{ }^{1}$, Zaina H. Safarini', Yousra M. Banijaber ${ }^{1}$,
} Ahmad Jaradat ${ }^{1,2}$, Faris Abushamma ${ }^{1,2}$ and Sa'ed H. Zyoud ${ }^{3,4,5^{*}}$ (B)

\begin{abstract}
Background: Lower urinary tract symptoms (LUTS) are prevalent among pregnant women. Several articles show the impact of LUTS on pregnant women's quality of life (QoL). This study was designed to examine the impact of nonpathological LUTS on QoL among pregnant Palestinian women.

Methods: A cross-sectional, hospital-based study was conducted on women who were pregnant and receiving regular antenatal care at the obstetrics and gynecology clinic in Rafidia Hospital, Palestine. This self-administered questionnaire included the Urinary Distress Inventory - short-form (UDI-6), the Incontinence Impact Questionnaire short-form (IIQ-7), the European Quality of Life scale - 5 dimensions (EQ-5D), and the European Quality of Life - visual analogue scale (EQ-VAS). A convenience sampling method was used. In addition to this, multiple linear regression analyses were performed aiming to identify variables that have a significant relationship with QoL (i.e. socio-demographic variables, UDI-6 score, and IIQ-7 score).

Results: This study included a total of 306 pregnant women. Participants had a mean age of 26.9 years (SD, 3.6). The subjects scored an average of $31.2 \pm 19.2$ out of 100 points for the UDI- 6 scale and an average of $31.9 \pm 24.9$ out of 100 points for the IIQ-7 scale. On the other hand, the subjects' average EQ-5D and EQ-VAS scores were $0.76 \pm 0.17$ and $67.96 \pm 19.28$ respectively. The subjects' responses on UDI-6 significantly correlated with their responses on both the EQ-5D and EQ-VAS scales ( $r=-0.338, p<0.001$ and $r=-0.206, p<0.001$, respectively). Likewise, their responses on IIQ-7 also significantly correlated with their responses on both the EQ-5D and EQ-VAS scales $(r=-0.389, p<0.001$ and $r=-0.329, p<0.001$, respectively). Regression analysis found that the UDI-6 score $(p=0.001)$ and IIQ-7 score $(p<0.001)$, were significantly and negatively associated with EQ-5D index scores.
\end{abstract}

Conclusions: Our study shows a remarkable correlation between LUTS and QoL among pregnant women. Further longitudinal studies are required to assess the status of LUTS in the pre-pregnancy stage to ascertain a more accurate assessment of LUTS or LUTS related intervention and its impact on QoL during pregnancy.

Keywords: Lower urinary tract symptoms, Quality of life, Pregnancy, Palestine

*Correspondence: saedzyoud@yahoo.com; saedzyoud@najah.edu ${ }^{3}$ Department of Clinical and Community Pharmacy, Department of Pharmacy, College of Medicine and Health Sciences, An-Najah National University, Nablus 44839, Palestine

Full list of author information is available at the end of the article

\section{Background}

Pregnancy is a physiological process that entails several multisystem changes [1]. Pathological conditions may appear during pregnancy such as Urinary tract infections (UTIs), pre-eclampsia, and gestational diabetes [2]. Few reports have been conducted to date to assess the 
impact of lower urinary tract symptoms (LUTS) during pregnancy [3-5]. LUTS can have negative effects on the social, physical, and emotional well-being of pregnant women [6]. Pregnancy-related LUTS, despite not being a pathological condition by definition, account for a significant amount of urinary distress and can affect quality of life (QoL) during pregnancy [7]. Moreover, the prevalence of urinary symptoms and distress during pregnancy could be under-reported due to the intimate nature of these symptoms [8].

QoL during pregnancy, with its effect on women's physical and mental health, is an important topic that can be directly affected by the presence of LUTS [9-11]. Several reports have been published in order to identify and manage these symptoms early in pregnancy, such as antenatal urinary incontinence screening, health education regarding risk factors for urinary incontinence, and highlighting the importance of early recognition and management [7].

In Palestine, there has been a growing interest in studying QoL indices in different populations and how this may be impacted by different variables and factors [1219]. However, the impact of LUTS on the QoL among pregnant women has not been examined before. Therefore, this study aimed to examine the impact of nonpathological LUTS on the overall QoL during pregnancy, and to identify factors that might directly affect the QoL. The merit of this study shadows the growing trend to integrate LUTS management into routine pregnancycare, and planning personalised care for pregnant women in relation to these symptoms based on their unique risks and needs. Our results provide key data from the clinical setting demonstrating the extent to which LUTS affects pregnant women's physical and psychological well-being. This in turn allows for better planning and establishment of management protocols for the problem in order to improve pregnancy and health outcomes in general. Finally, the current study will provide a reference point for health officials in order to assess the efficiency of any future interventions to address this problem.

\section{Methods}

\section{Study design}

This was a cross-sectional study that assessed the impact of LUTS on QoL during pregnancy. It used questionnaire-based interviews to collect data from the study subjects.

\section{Study setting and study population}

The survey took place at the obstetrics and gynecology clinic in Rafidia Hospital. The target population was pregnant women aged between 18 and 40 years. Data was collected between September 2019 and February 2020.
The appointments were undertaken between $8 \mathrm{AM}$ and 1 PM which are the official clinic hours allocated to conducting follow-up appointments for pregnant women in the studied clinic.

\section{Sample size and sampling method}

During the study period, the approximate number of pregnant women visiting the obstetrics and gynecology clinic at Rafidia Hospital was 1100. To determine the sample size required for analysis this number was used as a reference. Using the Raosoft sample size calculator, a sample size of 285 was determined by setting the response distribution at 0.50 , the error margin at $5 \%$, and the confidence interval at $95 \%$. The target sample size was increased to 306 participants in order to decrease erroneous outcomes and improve research reliability. The convenience sampling technique was used for participants' selection.

\section{Inclusion and exclusion criteria}

For inclusion in the study, participants were required to be female, pregnant, able to speak Arabic, aged between 18 and 40 years, and have no history of a psychiatric illness. They were also required to be visiting the obstetrics and gynecology clinic in Rafidia Hospital for a pregnancy-related reason. Patients who had an established diagnosis of a urogenital condition or history of urological surgery were excluded.

\section{Data collection tool}

For data collection, a four-section, Arabic-language questionnaire was used. Section one asked for the participants' demographics. The structured questionnaire used in this study was based on previously published studies [20-23]. The Urinary Distress Inventory - short version (UDI-6) and the Incontinence Impact Questionnaire Short Form (IIQ-7), were included in sections two and three respectively, to assess lower urinary tract symptoms including incontinence [20-22]. In the final section, we included the European Quality of Life scale 5 dimensions (EQ-5D) and the European Quality of Life visual analogue scale (EQ-VAS) [23, 24]. Data for this research was obtained through self-administered questionnaires. Physicians were available at all times to answer questions and explain any queries.

Section one asked the participants to fill in their age, weight, height, residency type, smoking status, employment status, education level, income, regular physical exercise, gestational trimester, parity (number of children), presence of psychiatric illness, medical disorders, long-term medication use, and previous surgeries. These factors were selected from those identified in previous studies that may affect QoL during pregnancy $[25,26]$. 
Participants were put into one of five age groups: $\leq 20$, 21-25 years, 26-30 years, 31-34 years, or $\geq 35$ years [27]. The body mass index (BMI) for pregnancy was measured as pre-pregnancy weight in kilograms divided by height in meters squared, on the basis of self-reported weight and height. Based on their calculated body mass index (BMI), participants were classified into one of four groups: obese group (BMI $\geq 30 \mathrm{~kg} / \mathrm{m}^{2}$ ), overweight group $\left(\mathrm{BMI}=25-29.9 \mathrm{~kg} / \mathrm{m}^{2}\right)$, normal-weight group $\left(\mathrm{BMI}=18.5-25 \mathrm{~kg} / \mathrm{m}^{2}\right)$, or the underweight group (BMI $<18.5 \mathrm{~kg} / \mathrm{m}^{2}$ ) [28].

In section two, we included the UDI- 6 - short version. Similar to its full version, UDI-6 was designed to assess the severity of urinary distress symptoms based on the level of discomfort experienced during the past month. UDI-6 contains six questions that cover three areas: irritative symptoms (items one and two), stress symptoms (items three and four), and obstructive or discomfort symptoms (items five and six). Participants answer each section by choosing one of four options: 'greatly', 'moderately', 'a little bit', and 'not at all'. Each answer received a number of points between zero and three, with 'greatly' receiving three points and 'not at all' receiving zero points. Therefore, the highest possible UDI score was 18 . The internal consistency of UDI, as previously tested by Cronbach's alpha test coefficient, was 0.720 . Permission to include the Arabic version of this tool in our study was granted by the developer [21].

In section three, we included IIQ-7 - short version. IIQ-7 is a tool designed to gauge the impact of urinary incontinence on life quality in women. As in its full version, IIQ-7 focuses on four areas: physical activity (items one and two), travel (items three and four), social relations (item five), and emotional wellbeing (items six and seven). The participant rated the severity of symptoms on a zero-to-three scale, with zero as the least severe, and three as the most severe [22]. Therefore, the highest possible IIQ-7 score was 21 . The internal consistency of this tool was previously tested and the reported Cronbach's alpha coefficient was 0.894 . We obtained approval to include the Arabic version of this tool in our study from its developer.

All scores for UDI-6 and IIQ-7 were converted to a scale of 0-100 to allow comparison across measures [29]. UDI-6 and IIQ-7 proved to be valid and reliable questionnaires for evaluating the subjective phases of urinary incontinence severity. They were helpful in characterising the severity of incontinence, accessing treatment effectiveness, and making treatment decisions [30, 31].

In section four, we included the EQ-5D and the EQVAS scales to evaluate the health status and QoL of our subjects. EQ-5D is a standardized tool used to assess health outcomes. It studies five separate aspects of health: anxiety/depression, pain/discomfort, self-care, mobility, and usual activities. The subject rates each section on a 5-level scale (no problems, slight problems, moderate problems, severe problems and extreme problems). There are 3125 possible health states, obtained by using one number from each section, ranging from 11,111 (full health) to 55,555 (worst health). In the current study, we included the Arabic version $[12,15-19,23]$ of EQ-5D in accordance with its developers' guidelines after receiving their approval to use it (ID: 35675). The EQ-5D score was calculated according to the United States General Population Score Algorithm (i.e. EQ-5D-5L Crosswalk Index Value Calculator) for measuring the index value by the value set (weights) [32]. The possible values of this algorithm ranged from -0.109 to 1 , with values below 0 representing states considered to be worse than death. The internal consistency for this tool was acceptable (Cronbach's alpha of 0.808). EQ-VAS, on the other hand, measures the subject's perspective of their life quality using a scale of $0-100$ points $[23,24]$.

\section{Statistical analysis}

We used IBM SPSS, version 21 for data analysis. We presented the data as frequencies and percentages for participants' characteristics, and as means and standard deviations for their questionnaire scores. Participants' scores on EQ-5D and EQ-VAS scales were presented as medians and interquartile ranges. We tested the variables' normality using the Kolmogorov-Smirnov test. Mann-Whitney and Kruskal-Wallis tests were implemented to test the contrast between different categories based on the participants' characteristics. Possible correlations between all scales were evaluated by Pearson correlation coefficients. The significance was assumed at $p$-value $<0.05$. We also carried out multiple linear regressions to predict the variables that had a significant relationship with QoL (EQ-5D and EQ-VAS scores as dependent variables). In our regression model, all variables with $p<0.05$ in univariate analysis were used. Multicollinearity between the selected independent variables was tested with a variance inflation factor (VIF). Any VIF values of $<3$ were considered to be appropriate due to a lack of collinearity.

\section{Results}

\section{Demographic and clinical characteristics}

A total of 306 participants took part in this study. Participants had a mean age of 26.9 years (SD, 3.6). The age and BMI categories which included the highest number of subjects were 21-30years and normal BMI range, (70.2, and $46.1 \%$, respectively). The majority of participants were educated to a university-level (71.2\%). Most subjects were housewives (77.8\%), and lived in a 
moderate-income household (48\%). Over one-third of our subjects $(41.2 \%)$ were pregnant in their third trimester. Only $8.2 \%$ had an established diagnosis of a chronic illness, and $10.1 \%$ practiced physical exercise regularly. Tables 1 and 2 summarise all demographic and clinical characteristics of the subjects.

\section{QoL assessment findings (EQ-5D and EQ-VAS scores)}

The participants' mean EQ-5D and EQ-VAS scores were $0.76 \pm 0.17$ and $67.96 \pm 19.28$, respectively. Table 1 shows the association between the characteristics of the participants and the scores achieved on the EQ-5D scale, whereas Table 2 presents the relationship between their characteristics and scores on the EQ-VAS scale. The participants' level of education significantly affected their scores on both EQ-5D and EQ-VAS scales ( $p$-values were 0.005 and 0.004 , respectively), whereas their level of income and history of previous chronic disease significantly correlated only with their EQ-VAS scores ( $p$-values were $<0.001$ and 0.008 , respectively).

\section{Urogenital symptoms' correlation with the QoL in pregnant women}

Regarding urinary distress observations, the subjects scored an average of $5.6 \pm 3.4$ out of 18 (31.2 \pm 19.2 out of 100) points for the UDI- 6 scale, and an average of $6.7 \pm 5.2$ out of $21(31.9 \pm 24.9$ out of 100$)$ points for the IIQ-7 scale. Table 3 presents the correlations between urogenital symptom scales and QoL scales in pregnant women. The participants' responses on UDI significantly correlated with their responses on both the EQ-5D and EQ-VAS scales $(\mathrm{r}=-0.338, p<0.001$ and $\mathrm{r}=-0.206$, $p$-value $<0.001$, respectively). Likewise, their responses on IIQ-7 also significantly correlated with their responses on both the EQ-5D and EQ-VAS scales $(r=-0.389$, $p<0.001$ and $\mathrm{r}=-0.329, p<0.001$, respectively). As expected, the participants' responses on the EQ-5D scale and EQ-VAS scale also showed significant correlation $(\mathrm{r}=0.329, p<0.001)$.

\section{Results of multiple linear regression analysis}

A multiple linear regression analysis was constructed according to BMI, educational level, UDI-6 score, and IIQ-7 score. Multiple linear regression models that were estimated to explore associations with the EQ-5D index score found that the UDI-6 score $(p=0.001)$ and the IIQ-7 score $(p<0.001)$ significantly and negatively correlated with the EQ-5D index score. The factors significantly associated with the EQ-5D index score based on multiple linear regression findings are illustrated in Table 4. There was no evidence of multicollinearity between independent variables (VIF ranged from 1.037-1.261).
The multiple linear regression analysis was performed by using the EQ-VAS score as a dependent variable after controlling for BMI, education level, income, presence of chronic disease, drug history, UDI-6 score, and IIQ-7 score (Table 5). This demonstrated that income ( $p$ value $=0.036$ ) was significantly and positively associated with EQ-VAS scores, whilst IIQ-7 scores $(p<0.001)$ significantly and negatively correlated with EQ-VAS scores.

The factors significantly associated with the EQ-VAS score based on multiple linear regression findings are illustrated in Table 5. There was no evidence of multicollinearity between independent variables (VIF ranged from 1.089-2.962).

\section{Discussion}

There is scanty data to describe the prevalence of LUTS during pregnancy and its negative effect on QoL, which we believe is prevalent in Palestine, and may negatively affect the physical and mental health of pregnant women. We used two assessment tools for urinary symptoms (UDI-6 and IIQ-7) and two life quality assessment tools (EQ-5D and EQ-VAS) in order to explore this problem. In addition to this, factors that may affect QoL have also been studied. It was appropriate to use a generalised questionnaire to determine the subject's health-related quality of life (HRQoL) values [33-36], given that most pregnant women do not have a fatal illness [37]. As one of the most common means for assessing the overall health of the body, EQ-5D is a powerful generic tool, particularly in regards to evaluating symptoms of pain and anxiety/depression [38]. In addition, IIQ-7 is a sevenitem questionnaire designed for the assessment of various QoL impairment areas [39]. The areas include social activities, moving far from home, mental wellbeing, household chores, entertainment activities, feelings of frustration, and physical recreation.

The mean EQ-5D in our study was $0.76 \pm 0.17$, whereas the mean EQ-VAS score was $67.96 \pm 19.28$. There was also a strong correlation between urinary distress symptoms assessment scores (UDI and IIQ-7) and QoL assessment scores (EQ-5D and EQ-VAS). Therefore our study confirms the hypothesis that LUTS during pregnancy has a detrimental effect on QoL, suggesting a negative impact on physical and mental health during pregnancy.

The participants' scores on QoL assessment scales showed significant correlations with some demographic variables such as BMI, education level, income level, history of other chronic illnesses, and use of chronic medication. This is supported by the Singaporean Integrated Women's Health Program findings which showed a notable association of BMI, parity, and education level with urinary distress symptoms and a higher likelihood of seeking medical care due to these symptoms [40]. 
Table 1 Association between the characteristics of the participants and the EQ-5D scores they achieved

\begin{tabular}{|c|c|c|c|}
\hline Characteristic & No. (\%); Total = 306 & $\begin{array}{l}\text { EQ-5D score } \\
\text { Median [Q1-Q3] }\end{array}$ & $P$-value* \\
\hline \multicolumn{4}{|l|}{ Age group (years) } \\
\hline$\leq 20$ & $22(7.2)$ & $0.79[0.68-0.82]$ & \multirow[t]{5}{*}{$0.323^{a}$} \\
\hline $21-25$ & $102(33.3)$ & $0.79[0.67-0.86]$ & \\
\hline $26-30$ & $113(36.9)$ & $0.79[0.65-0.88]$ & \\
\hline $31-35$ & $39(12.7)$ & $0.74[0.60-0.82]$ & \\
\hline$>35$ & $30(9.8)$ & $0.80[0.67-0.86]$ & \\
\hline \multicolumn{4}{|l|}{ BMI group } \\
\hline Healthy weight & $141(46.1)$ & $0.81[0.69-0.88]$ & \multirow[t]{3}{*}{$0.021^{a}$} \\
\hline Overweight & $118(38.6)$ & $0.77[0.65-0.83]$ & \\
\hline Obese & $47(15.4)$ & $0.74[0.60-0.83]$ & \\
\hline \multicolumn{4}{|l|}{ Education level } \\
\hline Elementary school & $4(1.3)$ & $0.76[0.63-0.81]$ & \multirow[t]{4}{*}{$0.005^{\mathrm{a}}$} \\
\hline Middle school & $18(5.9)$ & $0.79[0.71-0.84]$ & \\
\hline High school & $66(21.6)$ & $0.81[0.71-1.00]$ & \\
\hline University & $218(71.2)$ & $0.77[0.64-0.83]$ & \\
\hline \multicolumn{4}{|l|}{ Employment status } \\
\hline House-wife & $238(77.8)$ & $0.70[0.53-0.85]$ & \multirow[t]{3}{*}{$0.133^{a}$} \\
\hline Governmental employee & $31(10.1)$ & $0.65[0.50-0.80]$ & \\
\hline Private sector & $37(12.1)$ & $0.70[0.57-0.82]$ & \\
\hline \multicolumn{4}{|l|}{ Income } \\
\hline Low (<2000 NIS) & $123(40.2)$ & $0.79[0.64-0.86]$ & \multirow[t]{3}{*}{$0.577^{\mathrm{a}}$} \\
\hline Moderate (2000-4999 NIS) & $147(48)$ & $0.79[0.68-0.84]$ & \\
\hline High ( $\geq 5000$ NIS) & $36(11.8)$ & $0.80[0.66-0.88]$ & \\
\hline \multicolumn{4}{|l|}{ Gestational trimester } \\
\hline First trimester & $68(22.2)$ & $0.80[0.70-0.87]$ & \multirow[t]{3}{*}{$0.055^{\mathrm{a}}$} \\
\hline Second trimester & $112(36.6)$ & $0.80[0.68-0.87]$ & \\
\hline Third trimester & $126(41.2)$ & $0.75[0.63-0.83]$ & \\
\hline \multicolumn{4}{|l|}{ No. of children } \\
\hline 0 & $60(19.6)$ & $0.79[0.67-0.82]$ & \multirow[t]{5}{*}{$0.869^{a}$} \\
\hline 1 & $92(30.1)$ & $0.79[0.67-0.86]$ & \\
\hline 2 & 64 (20.9) & $0.80[0.63-0.96]$ & \\
\hline 3 & $44(14.4)$ & $0.77[0.65-0.84]$ & \\
\hline$\geq 4$ & $46(15.0)$ & $0.78[0.68-0.86]$ & \\
\hline \multicolumn{4}{|l|}{ Presence of chronic diseases } \\
\hline No & $281(91.8)$ & $0.79[0.68-0.86]$ & \multirow[t]{2}{*}{$0.154^{b}$} \\
\hline Yes & $25(8.2)$ & $0.74[0.63-0.83]$ & \\
\hline \multicolumn{4}{|l|}{ Drug history } \\
\hline No & $287(93.8)$ & $0.79[0.68-0.86]$ & \\
\hline \multirow[t]{2}{*}{ Yes } & $19(6.2)$ & $0.74[0.66-0.83]$ & \\
\hline & & & $0.361^{b}$ \\
\hline \multicolumn{4}{|l|}{ Regular exercise } \\
\hline No & $275(89.9)$ & $0.79[0.68-0.86]$ & \multirow[t]{2}{*}{$0.401^{b}$} \\
\hline Yes & $31(10.1)$ & $0.80[0.63-0.83]$ & \\
\hline
\end{tabular}

Abbreviations: BMI body mass index, EQ-5D European Quality of Life scale 5 dimensions, NIS New Israeli Shekel (1 New Israeli Shekel =0.29 US Dollar)

* All significant $p$-values are displayed in bold

a Calculated by Kruskal-Wallis test

b Calculated by Mann-Whitney $U$ test 
Table 2 Association between the characteristics of the participants and the EQ-VAS scores they achieved

\begin{tabular}{|c|c|c|c|}
\hline Characteristic & No. (\%); Total = 306 & $\begin{array}{l}\text { EQ-VAS score } \\
\text { Median [Q1-Q3] }\end{array}$ & $P$-value* \\
\hline \multicolumn{4}{|l|}{ Age group (years) } \\
\hline$\leq 20$ & $22(7.2)$ & 82.00 [68.00-90.00] & \multirow[t]{5}{*}{$0.260^{a}$} \\
\hline $21-25$ & $102(33.3)$ & $70.00[50.00-80.00]$ & \\
\hline $26-30$ & $113(36.9)$ & 70.00 [60.00-85.00] & \\
\hline $31-35$ & $39(12.7)$ & $60.00[45.00-80.00]$ & \\
\hline$>35$ & $30(9.8)$ & $72.50[63.75-86.25]$ & \\
\hline \multicolumn{4}{|l|}{ BMI group } \\
\hline Healthy weight & $141(46.1)$ & 70.00 [57.50-90.00] & \multirow[t]{3}{*}{$0.031^{a}$} \\
\hline Overweight & $118(38.6)$ & 70.00 [55.00-80.00] & \\
\hline Obese & $47(15.4)$ & $65.00[50.00-80.00]$ & \\
\hline \multicolumn{4}{|l|}{ Education level } \\
\hline Elementary school & $4(1.3)$ & 37.50 [27.50-40.00] & \multirow[t]{4}{*}{$0.004^{a}$} \\
\hline Middle school & $18(5.9)$ & $55.00[48.50-80.00]$ & \\
\hline High school & $66(21.6)$ & $70.00[50.00-81.25]$ & \\
\hline University & $218(71.2)$ & 70.00 [60.00-85.00] & \\
\hline \multicolumn{4}{|l|}{ Employment status } \\
\hline House-wife & $238(77.8)$ & $70.00[53.75-85.00]$ & \multirow[t]{3}{*}{$0.279^{a}$} \\
\hline Governmental employee & $31(10.1)$ & $65.00[50.00-80.00]$ & \\
\hline Private sector & $37(12.1)$ & $70.00[57.50-82.50]$ & \\
\hline \multicolumn{4}{|l|}{ Income } \\
\hline Low (<2000 NIS) & $123(40.2)$ & $65.00[50.00-80.00]$ & \multirow[t]{3}{*}{$<0.001^{\mathrm{a}}$} \\
\hline Moderate (2000-4999 NIS) & $147(48)$ & $70.00[55.00-80.00]$ & \\
\hline $\operatorname{High}(\geq 5000$ NIS) & $36(11.8)$ & 80.00 [70.00-90.00] & \\
\hline \multicolumn{4}{|l|}{ Gestational trimester } \\
\hline First trimester & $68(22.2)$ & 70.00 [60.00-80.00] & \multirow[t]{3}{*}{$0.152^{\mathrm{a}}$} \\
\hline Second trimester & $112(36.6)$ & $70.00[60.00-85.00]$ & \\
\hline Third trimester & $126(41.2)$ & 70.00 [50.00-80.00] & \\
\hline \multicolumn{4}{|l|}{ No. of children } \\
\hline 0 & $60(19.6)$ & 75.00 [60.00-90.00] & \multirow[t]{5}{*}{$0.136^{a}$} \\
\hline 1 & $92(30.1)$ & $70.00[60.00-85.00]$ & \\
\hline 2 & $64(20.9)$ & $70.00[55.00-80.00]$ & \\
\hline 3 & $44(14.4)$ & $70.00[50.00-80.00]$ & \\
\hline$\geq 4$ & $46(15.0)$ & $62.00[50.00-80.00]$ & \\
\hline \multicolumn{4}{|l|}{ Presence of chronic diseases } \\
\hline No & $281(91.8)$ & $70.00[57.50-85.00]$ & \multirow[t]{2}{*}{$0.008^{b}$} \\
\hline Yes & $25(8.2)$ & $60.00[40.00-70.00]$ & \\
\hline \multicolumn{4}{|l|}{ Drug history } \\
\hline No & $287(93.8)$ & $70.00[55.00-85.00]$ & \multirow[t]{2}{*}{$0.033^{b}$} \\
\hline Yes & $19(6.2)$ & $60.00[40.00-70.00]$ & \\
\hline \multicolumn{4}{|l|}{ Regular exercise } \\
\hline No & $275(89.9)$ & $70.00[50.00-80.00]$ & \multirow[t]{2}{*}{$0.532^{b}$} \\
\hline Yes & $31(10.1)$ & 80.00 [70.00-90.00] & \\
\hline
\end{tabular}

Abbreviations: BMI body mass index, EQ-VAS European Quality of Life visual analogue scale, NIS New Israeli Shekel (1 New Israeli Shekel =0.29 US Dollar)

* All significant $p$-values are displayed in bold

** We merged underweight and healthy weight groups as the former contained only 7 subjects

a Calculated by Kruskal-Wallis test

b Calculated by Mann-Whitney $U$ test 
Table 3 Correlation of urinary distress scales and quality of life scales among pregnant women

\begin{tabular}{lllll}
\hline Scales & $\begin{array}{l}\text { EQ-5D } \\
\boldsymbol{P} \text {-value }\end{array}$ & Correlation & $\begin{array}{l}\text { EQ-VAS } \\
\boldsymbol{P} \text {-value }\end{array}$ & Correlation \\
\hline UDI & $<0.001$ & -0.338 & $<0.001$ & -0.206 \\
IIQ-7 & $<0.001$ & -0.398 & $<0.001$ & -0.348 \\
EQ-5D & - & - & $<0.001$ & 0.329 \\
EQ-VAS & $<0.001$ & 0.329 & - & - \\
\hline
\end{tabular}

Abbreviations: EQ-VAS European Quality of Life visual analogue scale, EQ-5D European Quality of Life scale 5 dimensions, UD/ urinary distress inventory, IIQ-7 incontinence impact questionnaire - short form

Participants with higher socioeconomic status had a better QoL score, which is consistent with findings from other studies that revealed a significant association between socioeconomic status and urinary incontinence. Furthermore, this cohort of patients is more likely to seek medical advice and treatment in earlier stages [41]. LUTS is a newly evolving concept in urology, as well as a broad term that can be applied to many urological abnormalities, such as lower urinary tract infections, idiopathic overactive bladder symptoms, etc. In general, higherincome and educated females are more likely to lead a healthy lifestyle in regards to eating healthily and undertaking regular exercise, as well as being less exposed to anxiety and other mental health issues. All of these elements reduce the risk of developing LUTS symptoms $[41,42]$. This is also applicable to pregnant females, particularly as patients with a higher income have easier access to primary healthcare, allowing prompt treatment of LUTS and any underlying pathology. This observation should be taken into consideration if a screening program for LUTS were to be initiated, as prioritising lower-educated and lower-income females would likely identify a higher proportion of patients requiring treatment. Omitting higher-income and educated females from such a screening program would likely be a costeffective approach.

Table 4 Multiple linear regression analysis of the association of variables with EQ-5D scores

\begin{tabular}{|c|c|c|c|c|c|c|c|c|c|}
\hline \multicolumn{2}{|c|}{ Model } & \multicolumn{2}{|c|}{$\begin{array}{l}\text { Unstandardized } \\
\text { Coefficients }\end{array}$} & \multirow{2}{*}{$\begin{array}{l}\text { Standardized } \\
\text { Coefficients } \\
\text { Beta }\end{array}$} & \multirow[t]{2}{*}{$\mathrm{t}$} & \multirow[t]{2}{*}{$p$-value* } & \multicolumn{2}{|c|}{ 95.0\% Confidence Interval for B } & \multirow{2}{*}{$\begin{array}{l}\text { Collinearity } \\
\text { Statistics } \\
\text { VIF }\end{array}$} \\
\hline & & B & Std. Error & & & & Lower Bound & Upper Bound & \\
\hline \multirow[t]{5}{*}{1} & (Constant) & 1.045 & 0.058 & & 17.962 & 0.000 & 0.931 & 1.160 & \\
\hline & BMI & -0.013 & 0.013 & -0.052 & -0.966 & 0.335 & -0.038 & 0.013 & 1.108 \\
\hline & Education level & -0.037 & 0.014 & -0.040 & -.992 & 0.052 & -0.064 & 0.010 & 1.037 \\
\hline & UDI-6 score & -0.002 & 0.001 & -0.191 & -3.334 & 0.001 & -0.004 & -0.001 & 1.261 \\
\hline & IIQ-7 score & -0.002 & 0.000 & -0.330 & -5.927 & 0.000 & -0.003 & -0.002 & 1.196 \\
\hline
\end{tabular}

$B M I$ body mass index, VIF variance inflation factor, EQ-5D European quality of life scale 5 dimensions, UD/ urinary distress inventory, IIQ incontinence impact questionnaire

* All significant p-values are displayed in bold

Table 5 Multiple linear regression analysis of the association between factors and EQ-VAS score

\begin{tabular}{|c|c|c|c|c|c|c|c|c|c|}
\hline \multicolumn{2}{|c|}{ Model } & \multicolumn{2}{|c|}{$\begin{array}{l}\text { Unstandardized } \\
\text { Coefficients }\end{array}$} & \multirow{2}{*}{$\begin{array}{l}\text { Standardized } \\
\text { Coefficients } \\
\text { Beta }\end{array}$} & \multirow[t]{2}{*}{$\mathrm{t}$} & \multirow[t]{2}{*}{$p$-value* } & \multicolumn{2}{|c|}{$95.0 \%$ Confidence Interval for B } & \multirow[b]{2}{*}{ VIF } \\
\hline & & B & Std. Error & & & & Lower Bound & Upper Bound & \\
\hline \multirow[t]{8}{*}{1} & (Constant) & 69.385 & 8.852 & & 7.839 & 0.000 & 51.965 & 86.804 & \\
\hline & BMI & -0.669 & 1.508 & -0.025 & -0.444 & 0.657 & -3.637 & 2.298 & 1.140 \\
\hline & Education level & 2.665 & 1.674 & 0.091 & 1.592 & 0.113 & -0.630 & 5.960 & 1.162 \\
\hline & Income & 3.373 & 1.604 & 0.116 & 2.102 & 0.036 & 0.215 & 6.530 & 1.089 \\
\hline & $\begin{array}{l}\text { Presence of } \\
\text { chronic diseases }\end{array}$ & -7.004 & 7.401 & -0.100 & -0.946 & 0.345 & -21.569 & 7.562 & 2.962 \\
\hline & Drug history & 1.251 & 8.509 & 0.016 & 0.147 & 0.883 & -15.494 & 17.997 & 2.065 \\
\hline & UDI-6 score & -0.110 & 0.080 & -0.082 & -1.371 & 0.171 & -0.269 & 0.048 & 1.285 \\
\hline & IIQ-7 score & -0.217 & 0.045 & -0.280 & -4.821 & 0.000 & -0.306 & -0.129 & 1.209 \\
\hline
\end{tabular}

$B M I$ body mass index, EQ-VAS European Quality of Life visual analogue scale, UDI urinary distress inventory, IIQ incontinence impact questionnaire, VIF variance inflation factor

* All significant $p$-values are displayed in bold 
We also uncovered a significant correlation between the severity of the urinary distress symptoms (using both UDI-6 and IIQ-7 scales) and the subject's QoL. This emphasises the bothersome nature of these symptoms. This observation is in concordance with an increasing understanding of the fundamental effect of urinary incontinence symptoms on quality of life, and the importance of surveying and managing these symptoms as early as possible [43]. Proper and timely intervention for these problems should be of particular importance, as due to the intimate nature of urinary distress symptoms, affected women often delay seeking medical help.

\section{Limitations and strengths}

One of the limitations of this study was the cross-section design, which prevented us from interpreting the causality of significant associations in our results. Another limitation of this study is that it took place in one hospital, which may limit the generalisability of our data to all pregnant women in Palestine. However, this study had strengths as well, such as using two urinary distress assessment tools and two QoL tools that have proven validity, which attest to the accuracy of our assessment. The most fundamental limitation lies in the fact that we wanted to exclude any established diagnosis of lower urinary tract abnormalities, therefore our exclusion criteria mandates omission of subjects with any previously established diagnosis of urinary tract abnormalities or previous urological surgeries. Nevertheless, we do believe that a small percentage of pregnant females could have had overactive bladder symptoms prior to pregnancy which became more prominent or distressing during pregnancy. We did not go back and try to review all symptoms prior to pregnancy, as our goal was to assess the prevalence of LUTS during pregnancy and its impact on QoL. An additional question that was not addressed in this study was whether the effect on bladder function alters during different trimesters. Whilst we have the data available and could have undertaken sub-analysis, we felt the sample size too small to present viable conclusions. Therefore, we preferred to analyse the data as a whole, rather than sub-classifying it. Furthermore, the absence of control groups (i.e. pregnant versus non-pregnant) limits the interpretation of the disease burden on HRQoL.

Moreover, this was the first study to examine urinary distress symptoms' impact on the QoL during pregnancy in Palestine. As our study focus was towards pregnancy-associated, non-pathological LUTS, all of our participants had received a first-trimester negative urine test, and were screened for fever symptoms and dysuria at the time of the questionnaire. Patients with pre-existing urogenital conditions and a history of urological surgery were also excluded, as mentioned previously. Understanding of Pregnancy-associated LUTS/ Pregnancy non-pathological LUTS/ LUTS during pregnancy is an evolving concept in the literature [44] and we took the first step in the Middle East to evaluate its presence, risk factors, and impact on QoL.

\section{Conclusions}

There is a remarkable correlation between the severity of urinary distress symptoms and the QoL among pregnant women. Identification and characterisation of HRQoL-related factors in pregnant women with LUTS can potentially accelerate the development of diagnostic, preventive, and therapeutic strategies for the improvement of HRQoL in this population. Alerting healthcare providers to the presence of LUTS among pregnant women is recommended. Focusing on the prevention of risk factors for LUTS is necessary in order to minimise its detrimental effect on QoL. Further longitudinal studies are required to assess the status of LUTS in the pre-pregnancy stage and ascertain a more accurate assessment of LUTS and LUTS related intervention and its impact on QoL during pregnancy. Several strategies can be adapted to recognise and treat this problem from an early stage, such as communitybased counselling for pregnant females and regular assessment of LUTS during different stages of pregnancy. Therefore, healthcare providers should consider the psychological effects of LUTS on pregnant women in order to raise and deal with possible evolving mental health issues through different trimesters.

\section{Abbreviations}

UTIs: Urinary tract infections; LUTS: Lower urinary tract symptoms; QoL: Quality of life; HRQoL: Health-related quality of life; NNU: An-Najah National University; NIS: New Israeli Shekel; UI: Urinary incontinence; EQ-5D: European Quality of Life scale 5 dimensions; UDI: Urinary distress inventory; IQ: Incontinence impact questionnaire; EQ-VAS: European Quality of Life visual analogue scale; OBGYN: Obstetrics and gynecology; IRB: Institutional Review Board; VIF: Variance inflation factor.

\section{Acknowledgements \\ The authors thank Samantha Kearley from the Bristol Urological Institute, UK for English editing of the manuscript.}

\section{Authors' contributions}

JS and QA collected and analyzed the data, performed literature review and contributed to manuscript drafting. AS conducted data analysis and literature review and partially interpreted the data and drafted the manuscript. DJ, YB and ZS performed data collection and literature review. AJ and FA participated in the conception and design of the study and data interpretation, and revised the manuscript critically for strengthening intellectual contents. SZ played a key role in conceptualization, designing, coordination, supervision of this study and took the responsibility of the integrity of the data and the accuracy of the analysis; he also conducted a critical review of results' interpretation, revised the manuscript critically for strengthening intellectual contents, and took part in the final writing. All authors read the final manuscript and approve of it. 


\section{Funding}

No specific grant was received from any public, commercial or non-profit funding agency for this research.

\section{Availability of data and materials}

All datasets collected and analyzed in this survey will be available by the corresponding author upon any reasonable request.

\section{Ethics approval and consent to participate}

We began this study after obtaining approval from the Institutional Review Board of An-Najah National University, and the approval from the Palestinian Ministry of Health. Our questionnaire also contained written informed consent and attached to each questionnaire that respondents had read and voluntarily accepted prior to the continuation of the other questions.

\section{Consent for publication}

Does not apply.

\section{Competing interests}

All authors declare there are no competing interests.

\section{Author details}

${ }^{1}$ Department of Medicine, College of Medicine and Health Sciences, AnNajah National University, Nablus 44839, Palestine. ${ }^{2}$ Department of Urology, An-Najah National University Hospital, Nablus 44839, Palestine. ${ }^{3}$ Department of Clinical and Community Pharmacy, Department of Pharmacy, College of Medicine and Health Sciences, An-Najah National University, Nablus 44839, Palestine. ${ }^{4}$ Poison Control and Drug Information Center (PCDIC), College of Medicine and Health Sciences, An-Najah National University, Nablus 44839, Palestine. ${ }^{5}$ Clinical Research Center, An-Najah National University Hospital, Nablus 44839, Palestine.

Received: 3 August 2020 Accepted: 25 November 2020 Published online: 04 December 2020

\section{References}

1. Soma-Pillay P, Nelson-Piercy C, Tolppanen H, Mebazaa A. Physiological changes in pregnancy. Cardiovasc J Afr. 2016;27(2):89-94.

2. Narayan B, Nelson-Piercy C. Medical problems in pregnancy. Clin Med (Lond). 2017;17(3):251-7.

3. Balik G, Güven ES, Tekin YB, Şentürk Ş, Kağitci M, Üstüner I, Mete Ural Ü, Şahin FK. Lower urinary tract symptoms and urinary incontinence during pregnancy. Low Urin Tract Symptoms. 2016;8(2):120-4.

4. Martins G, Soler ZA, Cordeiro JA, Amaro JL, Moore KN. Prevalence and risk factors for urinary incontinence in healthy pregnant Brazilian women. Int Urogynecol J. 2010;21(10):1271-7.

5. Liang CC, Chang SD, Lin SJ, Lin YJ. Lower urinary tract symptoms in primiparous women before and during pregnancy. Arch Gynecol Obstet. 2012;285(5):1205-10.

6. van der Vaart $\mathrm{CH}$, de Leeuw JR, Roovers JP, Heintz AP. Measuring healthrelated quality of life in women with urogenital dysfunction: the urogenital distress inventory and incontinence impact questionnaire revisited. Neurourol Urodyn. 2003;22(2):97-104.

7. Mohd Yusoff D, Awang S, Kueh YC. Urinary incontinence among pregnant women attending an antenatal clinic at a tertiary teaching hospital in North-East Malaysia. J Taibah Univ Sci. 2018;14(1):39-46.

8. Narchi NZ. Prenatal care by nurses in the east zone of the city of Sao Paulo - Brazil. Rev Esc Enferm USP. 2010;44(2):266-73.

9. Herath INS, Balasuriya A, Sivayogan S. Physical and psychological morbidities among selected antenatal females in Kegalle district of Sri Lanka: a cross sectional study. J Obstet Gynaecol. 2017;37(7):849-54.

10. van Brummen HJ, Bruinse HW, van der Bom JG, Heintz AP, van der Vaart $\mathrm{CH}$. How do the prevalences of urogenital symptoms change during pregnancy? Neurourol Urodyn. 2006;25(2):135-9.

11. Mallah F, Montazeri A, Ghanbari Z, Tavoli A, Haghollahi F, Aziminekoo E. Effect of urinary incontinence on quality of life among Iranian women. J Family Reprod Health. 2014;8(1):13-9.
12. Barham A, Ibraheem R, Zyoud SH. Cardiac self-efficacy and quality of life in patients with coronary heart disease: a cross-sectional study from Palestine. BMC Cardiovasc Disord. 2019;19(1):290.

13. Khatib ST, Hemadneh MK, Hasan SA, Khazneh E, Zyoud SH. Quality of life in hemodialysis diabetic patients: a multicenter cross-sectional study from Palestine. BMC Nephrol. 2018;19(1):49.

14. Alami YZ, Ghanim BT, Zyoud SH. Epworth sleepiness scale in medical residents: quality of sleep and its relationship to quality of life. J Occup Med Toxicol. 2018;13:21.

15. Abu Farha NH, Khatib MT, Salameh H, Zyoud SH. Cancer-related posttreatment pain and its impact on health-related quality of life in breast cancer patients: a cross sectional study in Palestine. Asia Pac Fam Med. 2017:16:7.

16. Zyoud SH, Daraghmeh DN, Mezyed DO, Khdeir RL, Sawafta MN, Ayaseh NA, Tabeeb GH, Sweileh WM, Awang R, Al-Jabi SW. Factors affecting quality of life in patients on haemodialysis: a cross-sectional study from Palestine. BMC Nephrol. 2016;17(1):44.

17. Al-Jabi SW, Zyoud SH, Sweileh WM, Wildali AH, Saleem HM, Aysa HA, Badwan MA, Awang R. Relationship of treatment satisfaction to healthrelated quality of life: findings from a cross-sectional survey among hypertensive patients in Palestine. Health Expect. 2015;18(6):3336-48.

18. Zyoud SH, Al-Jabi SW, Sweileh WM, Wildali AH, Saleem HM, Aysa HA, Badwan MA, Awang R, Morisky DE. Health-related quality of life associated with treatment adherence in patients with hypertension: a crosssectional study. Int J Cardiol. 2013;168(3):2981-3.

19. Zyoud SH, Al-Jabi SW, Sweileh WM, Arandi DA, Dabeek SA, Esawi HH, Atyeh RH, Abu-Ali HA, Sleet Yl, Abd-Alfatah BM, et al. Relationship of treatment satisfaction to health-related quality of life among Palestinian patients with type 2 diabetes mellitus: findings from a cross-sectional study. J Clin Transl Endocrinol. 2015;2(2):66-71.

20. Uebersax JS, Wyman JF, Shumaker SA, McClish DK, Fantl JA. Short forms to assess life quality and symptom distress for urinary incontinence in women: the incontinence impact questionnaire and the urogenital distress inventory. Continence program for women research group. Neurourol Urodyn. 1995;14(2):131-9.

21. Altaweel W, Seyam R, Mokhtar A, Kumar P, Hanash K. Arabic validation of the short form of urogenital distress inventory (UDI-6) questionnaire. Neurourol Urodyn. 2009;28(4):330-4.

22. Ghroubi S, El Fani N, Elarem S, Alila S, Ben Ayed H, Borgi O, Chmak J, Elleuch $\mathrm{MH}$. Arabic (Tunisian) translation and validation of the urogenital distress inventory short form (UDI-6) and incontinence impact questionnaire short form (IIQ-7). Arab J Urol. 2020;18(1):27-33.

23. Horowitz E, Abadi-Korek I, Shani M, Shemer J. EQ-5D as a generic measure of health-related quality of life in Israel: reliability, validity and responsiveness. Isr Med Assoc J. 2010;12(12):715-20.

24. EuroQol Research Foundation. EQ-5D-5L User Guide. 2019. https://euroq ol.org/publications/user-guides. Accessed 15 May 2020.

25. RezaeiNiaraki M, Roosta S, Alimoradi Z, Allen KA, Pakpour AH. The association between social capital and quality of life among a sample of Iranian pregnant women. BMC Public Health. 2019;19(1):1497.

26. Lagadec N, Steinecker M, Kapassi A, Magnier AM, Chastang J, Robert S, Gaouaou N, Ibanez G. Factors influencing the quality of life of pregnant women: a systematic review. BMC Pregnancy Childbirth. 2018;18(1):455.

27. Alzboon $G$, Vural G. Factors influencing the quality of life of healthy pregnant women in North Jordan. Medicina (Kaunas). 2019;55(6):278.

28. Klatsky AL, Zhang J, Udaltsova N, Li Y, Tran HN. Body mass index and mortality in a very large cohort: is it really healthier to be overweight? Perm J. 2017;21:16-142.

29. Utomo E, Korfage IJ, Wildhagen MF, Steensma AB, Bangma CH, Blok BF. Validation of the urogenital distress inventory (UDI-6) and incontinence impact questionnaire (IIQ-7) in a Dutch population. Neurourol Urodyn. 2015;34(1):24-31.

30. Nusee Z, Rusly A, Jamalludin AR, Abdulwahab DF, Ismail R. Translation and validation of Bahasa Malaysia version of urogenital distress inventory (UDI-6) and incontinence impact quality of life questionnaires (IIQ-7) a Cross Sectional Study. Malays J Med Sci. 2016;23(3):57-63.

31. Lasserre A, Pelat C, Gueroult V, HanslikT, Chartier-Kastler E, Blanchon T, Ciofu C, Montefiore ED, Alvarez FP, Bloch J. Urinary incontinence in French women: prevalence, risk factors, and impact on quality of life. Eur Urol. 2009;56(1):177-83. 
32. Visser E, de Bock GH, Kollen BJ, Meijerink M, Berger MY, Dekker JH. Systematic screening for urinary incontinence in older women: who could benefit from it? Scand J Prim Health Care. 2012;30(1):21-8.

33. Heslin M, Chua KC, Trevillion K, Nath S, Howard LM, Byford S. Psychometric properties of the five-level EuroQoL-5 dimension and short Form-6 dimension measures of health-related quality of life in a population of pregnant women with depression. BJPsych Open. 2019;5(6):e88.

34. Morin M, Claris O, Dussart C, Frelat A, De Place A, Molinier L, Matillon Y, Ehlinger $V$, Vayssiere C. Quality of life during pregnancy: is there a link with breastfeeding at birth? Breastfeed Med. 2020;15(5):321-30.

35. Sut HK, Asci O, Topac N. Sleep quality and health-related quality of life in pregnancy. J Perinat Neonatal Nurs. 2016;34(4):302-9.

36. Morin M, Claris O, Dussart C, Frelat A, de Place A, Molinier L, Matillon Y, Elhinger $V$, Vayssiere $C$. Health-related quality of life during pregnancy: a repeated measures study of changes from the first trimester to birth. Acta Obstet Gynecol Scand. 2019;98(10):1282-91.

37. Ming WK, Wu H, Wu Y, Chen H, Meng T, Shen Y, Wang Z, Huang X, Sun W, Chow TS, et al. Health-related quality of life in pregnancy with uterine fibroid: a cross-sectional study in China. Health Qual Life Outcomes. 2019:17(1):89.

38. Sarkin AJ, Groessl EJ, Carlson JA, Tally SR, Kaplan RM, Sieber WJ, Ganiats TG. Development and validation of a mental health subscale from the quality of well-being self-administered. Qual Life Res. 2013;22(7):1685-96.

39. El-Azab AS, Mascha EJ. Arabic validation of the urogenital distress inventory and adapted incontinence impact questionnaires--short forms. Neurourol Urodyn. 2009;28(1):33-9.
40. Ng KL, Ng KWR, Thu WPP, Kramer MS, Logan S, Yong EL. Risk factors and prevalence of urinary incontinence in mid-life Singaporean women: the integrated Women's health program. Int Urogynecol J. 2020;31(9):1829-37.

41. Lee JA, Johns TS, Melamed ML, Tellechea L, Laudano M, Stern JM, Abraham NE. Associations between socioeconomic status and urge urinary incontinence: an analysis of NHANES 2005 to 2016. J Urol. 2020;203(2):379-84

42. Biswas B, Bhattacharyya A, Dasgupta A, Karmakar A, Mallick N, Sembiah S. Urinary incontinence, its risk factors, and quality of life: a study among women aged 50 years and above in a rural health Facility of West Bengal. J Midlife Health. 2017;8(3):130-6.

43. Aoki Y, Brown HW, Brubaker L, Cornu JN, Daly JO, Cartwright R. Urinary incontinence in women. Nat Rev Dis Primers. 2017;3:17042.

44. Li Z, Xu T, Zhang L, Zhu L. Prevalence, potential risk factors, and symptomatic bother of lower urinary tract symptoms during and after pregnancy. Low Urin Tract Symptoms. 2019;11(4):217-23.

\section{Publisher's Note}

Springer Nature remains neutral with regard to jurisdictional claims in published maps and institutional affiliations.
Ready to submit your research? Choose BMC and benefit from:

- fast, convenient online submission

- thorough peer review by experienced researchers in your field

- rapid publication on acceptance

- support for research data, including large and complex data types

- gold Open Access which fosters wider collaboration and increased citations

- maximum visibility for your research: over 100M website views per year

At BMC, research is always in progress.

Learn more biomedcentral.com/submissions 